\title{
Navigating a revision
}

\section{David P Stevens}

There is the story-probably apocryphalof the avid sailor, a retired physician, who lives on the Northeast US Atlantic coast and is said to host an unusual annual autumn beachfront gathering. His closest friends join him for the burning to the ground of a beloved sailing craft, generally a small wooden boat that he had spent the previous winter building in his workshop. First-time attendees are generally surprised that he insists this is actually a celebration.

It is part of an annual revision process. $\mathrm{He}$ follows the beachfront event with highly reflective design work. Then, in the dark days of a New England winter, he builds a new boat. He employs two simple rules for revision. First, capture the best of the accumulated design elements from the previous year's craft and, second, assure that the new design incorporates all that is new and innovative. In the spring, he launches anew. That's what the editor in me calls a proper revision!

\section{THE REVISION AHEAD: OSHC TO BECOME BMJ-0\&S}

This is the last issue of Quality and Safety in Health Care. A major revision will launch in January 2011 as BMJ-Quality and Safety. It holds the promise and excitement of the first breezy clear day in spring. BMJ-Q\&S will be led by a new editorial team. It will be supported by new and generous financial resources. There will be a new journal cover. It will be published monthly, so authors will see their accepted work in print more promptly. Online First will post papers to the journal's website as soon as page proofs are complete, so readers will have even more rapid access online to new reports.

But the most challenging revision will lie inevitably in the journal's evolving content-each new issue providing a fresh iteration of healthcare improvement scholarship. That process will of course be in the hands of the new editorial team, but also the authors, reviewers, and readers of BMJ-Q\&S.

Correspondence to David P Stevens, Adjunct Professor, Dartmouth Institute for Health Policy and Clinical Care, 30 Lafayette Street, Lebanon, NH 03766, USA; david.p.stevens@dartmouth.edu

\section{HEADWINDS AND STEERING WINDS}

Sailors know the difference between headwinds and steering winds. Headwinds are at the water's surface. A sailor friend of mine recently said that sailing into a headwind in a race is what separates experts from novices.

Steering winds, on the other hand, are the upper level currents that steer large weather fronts. At best, one can only track the effects of steering winds on other events. For example, steering winds guided Hurricane Earl safely away from my house at the last minute last July.

The most memorable review I ever received was for a paper that had been through at least a dozen revisions by its coauthors and reflected the work of a group of highly committed colleagues. I had optimistically submitted it to a high impact US medical journal that rejected it in fairly short order. One of the reviews I received was brief and direct: "This is not currently written as a scientific article. Everything is described in a vague manner... nothing is specific; what are registries, how are indicators measured... very vague, not written as a scientific article." For an earnest author, that's a proper headwind.

I did what I usually do when I receive a strongly negative review. I put it in the bottom drawer of my desk. Several weeks later I went back and retrieved all the reviews. Fortunately, 3 others effectively contributed to a much-improved revision, and it ultimately found its way to publication. ${ }^{1}$

I recently reflected again on the distance that separated this first reviewer's scientific world from mine-the abyss between two perspectives of healthcare science. ${ }^{2}$ How we are educated and trained as scholars has a profound influence on how we define the world around us, and particularly how we perceive science. Such an epistemological hierarchy in medicine constitutes a considerable headwind for improvement scholarship, but it is increasingly more effectively navigated by healthcare improvement scholars.

The steering winds that influence scholarly healthcare improvement are many but two deserve mention. One of the strongest is limited economic resources for support of healthcare everywhere around the world. The second is the political demand by societies everywhere for universal quality and safety in healthcare, which was captured by the US National Academy of Sciences Crossing the Chasm Report-timely, safe, efficient, effective patient-centered care. ${ }^{3}$ These winds will inevitably steer health systems and governments toward the necessity to find better, cheaper ways to care for their populations. Healthcare improvement scholars must capture these currents.

Six years ago a new editorial team proposed three aims for $\mathrm{OSHC}^{4}$ : first, more rigorous scholarship; second, spread of improvement to a more general medical audience and other health professionals; and third, accelerate improvement knowledge for the next generation of health profession students and trainees. Over time, authors, reviewers and readers have made these design elements familiar in OSHC and elsewhere. ${ }^{5-7}$

\section{BON VOYAGE}

Now there is a sleeker design in place. And BMJ-Q\&S lies in fresh and expert editorial hands. The fundamental task still comes down to making a space to report critically the work of improvement practitioners and scholars that employs the best and most rigorous improvement science. But the greater challenge will be to navigate the headwinds and exploit the steering winds so that the ultimate beneficiaries of our work-patients, health professionals, and health systems-will have more rapid access to the knowledge for healthcare improvement.

My heartfelt gratitude to BMJ, my associate editors and all the authors, reviewers and readers who have made this such a rewarding personal journey. Bon voyage to the new editorial team.

Competing interests The author is editor-in-chief of Quality and Safety in Health Care.

Provenance and peer review Not commissioned; not externally peer reviewed.

Oual Saf Health Care 2010;19:469-470

doi:10.1136/qshc.2010.049932

\section{REFERENCES}

1. Stevens DP, Bowen JL, Johnson JK, et al. A multiinstitutional quality improvement initiative to transform education for chronic illness care in resident continuity practices. J Gen Int Med 2010; 25(Suppl 4):639-43

2. Batalden PB, Davidoff F. What is "quality improvement" and how can it transform health care. Oual Saf Health Care 2007;16:2-3.

3. Institute of Medicine. Crossing the Quality Chasm: A New Health System for the Twenty-First Century. Washington, DC. The National Academy Press, 2001. 
4. Stevens DP. Three questions for QSHC. Qual Saf Health Care 2005;14:2-3.

5. Davidoff F, Batalden P, Stevens D, et al; the SQUIRE development group. Publication guidelines for quality improvement in health care: evolution of the SQUIRE project. Qual Saf Health Care 2008;17:13-9.

6. Bate $\mathbf{P}$, Mendel P, Robert G. Organizing for Quality: The improvement journeys of leading hospitals in Europe and the United States. Oxford: Radcliffe Publishing, 2008.
7. Seiden SC, Galvan C, Lamm R. Role of medical students in preventing harm and enhancing patient safety. Qual Saf Health Care 2006;15:272-6. 